\title{
Improving Regulatory Governance
}

\author{
Walter B. Kielholz ${ }^{\mathrm{a}}$ and Rolf Nebel ${ }^{\mathrm{b}}$ \\ ${ }^{a}$ Chairman of Credit Swiss Group and Vice-Chairman Swiss Re Group, CH-8022 Zurich, Switzerland. \\ ${ }^{\mathrm{b}}$ Regulatory and Government Affairs, Swiss Re Group, CH-8022 Zurich, Switzerland. \\ E-mail: Rolf_Nebel@swissre.com
}

In this paper the authors show the rationale behind the changes in the regulatory environment - with regulation moving toward a more risk-sensitive capital adequacy system and stronger risk governance - and their economic impact and influence on the management function.

The Geneva Papers (2005) 30, 34-42. doi:10.1057/palgrave.gpp.2510020

Keywords: supervision and regulation; insurance

\section{Introduction}

Over the past few years, the regulatory framework for supervision of the financial services industry has been undergoing profound reform. Regulation is moving towards a more risk-sensitive capital adequacy system and stronger risk governance. These changes in the regulatory environment have far-reaching implications for the industry, and even now, regulatory developments have become a top strategic challenge for the executive management of almost every major financial institution. Senior managers need to prepare their firms to cope with the new prudential requirements, which will absorb significant resources over the next few years. International standards on prudential supervision and financial disclosure are continuing their rapid expansion, compounding further the industry's compliance burden. In an attempt to address this issue from a broad perspective, this paper will highlight four aspects, all of which relate to regulatory governance and economics:

- the international standard-setters,

- the economic rationale behind the regulations,

- the economic impact of regulations, and

- their impact on the management function.

\section{International standard-setters}

International institutions are a major driving force behind the current reform of financial services regulation. These include institutions such as the Basel Committee on Banking Supervision, the International Association of Insurance Supervisors (IAIS), or the International Accounting Standards Board (IASB). Their international standards on disclosure, prudential supervision, and corporate governance are seen by lawmakers in most countries as minimum requirements for good regulatory governance that cannot be ignored. Most prominent among these standards are the new Basel Capital Accord, or "Basel II", and the International 
Financial Reporting Standards (IFRS). Also, we see the principles and standards adopted by the IAIS being taken as a benchmark for regulatory reform in the insurance sector.

The increasing influence of international standards in the financial services sector can be explained by the industry's globalization as well as by a related factor: the greater interdependency of financial risks. Internationally harmonized rules are deemed necessary to create a "level playing field" aimed at facilitating mutual recognition of prudential supervision. Indeed, there is consensus - and not just among regulators - that a common basis of sound prudential regulations would enhance the stability of the international financial system.

The standard-setting process in the financial services sector is accompanied by a growing number of reports and policy papers issued by various international organizations such as the OECD, the IMF, the Financial Stability Forum, and the Joint Forum. These papers provide the impetus for further international standardsetting and also serve as a reference for many regulatory reform processes at the national (and European Union, EU) level. With regard to the convergence of solvency systems in the insurance sector, the recently published report by the International Association of Actuaries (IAA) on the subject of a global framework for assessing insurer solvency is of particular importance. ${ }^{1}$ The elaboration of a risk-based capital framework is a highly technical matter that requires expert knowledge. It is thus not surprising that the number of people effectively involved in this standard-setting process is relatively small. This could give rise to the impression that international harmonization of prudential standards is in effect steered by a small number of key individuals.

While most international standards qualify as "soft law", they have a strong legitimizing function for national and supra-national lawmakers. The commitment made by governments (and the EU Commission) to embody international standards in national (and EU) law leaves little leeway for lawmaking institutions to amend the draft regulations. Indeed, international standard-setters could pose a challenge to democratic legislative systems that are based on checks and balances.

Against this background, there is a need for an independent political review process capable of ensuring that international standards comply with the principles of good regulatory governance. But what body could assume such a review function? One institution with a high profile and expertise in regulatory governance is the OECD. Over time, it has developed various policy recommendations and guidelines aimed at helping governments improve regulatory quality. The OECD Regulatory Reform Programme could be further developed and adapted to promote regulatory best practice in the area of international standards on financial services. An essential part of such quality control on the standard-setters would be to ensure that new regulations are based on a clear economic rationale, and that economic impact assessments are conducted prior to adopting the regulation.

\footnotetext{
${ }^{1}$ International Association of Actuaries (2004).
} 


\section{Economic Rationale Behind the Regulations}

In light of the increasing number and complexity of risk-based capital regulations, policymakers may find it helpful, from time to time, to step back and recall the basic objectives that underlie the regulation of financial services. They might also ask themselves which regulatory approach (or perhaps even which alternatives to regulation) would be most suitable. Policymakers need to be aware that prudential regulations are a type of state intervention and that such intervention should always pursue a legitimate public policy objective. Regulatory action should be guided (and limited) by a clear understanding of the underlying economic rationale.

The primary goal of prudential regulations is to protect the consumer. To understand why it is necessary to expand regulation, one must consider the way savings patterns have changed in recent years. Financial disintermediation (wider participation by individuals in many financial markets) has led to the emergence of innovative financial products catering to different investor needs and designed to deliver higher returns. There is wider use of sophisticated products such as unit-linked life policies, assetbacked securities, hedge funds, and structured products featuring a mix of financial techniques. Ideally, these products should be no less transparent with regard to the risk they entail, despite their greater complexity - and that is where regulation comes in.

Yet here it is important to distinguish between retail and wholesale business. Retail buyers of securities, for example, are dependent on their brokers' advice and research; and individuals purchasing long-term savings products often do not have enough insight into the mathematics and risks that underlie the product. Such consumers need protection.

Where wholesale business is concerned, however, there is no direct prudential rationale for protecting the mature, professional buyer of a financial service. It is thus not clear why supervision of reinsurance, for example, should be strengthened. Reinsurance is not sold to the general public; it is a business-to-business financial service provided to direct insurers, and in this instance, consumer protection is not a convincing justification for state supervision.

A fundamental function of most regulations of financial services is to address the problem of asymmetric information and resulting market imperfections. Thus, enhanced disclosure requirements are being proposed, aimed at improving transparency. The prudential objective behind public disclosure rules is to enhance market discipline. However, excessive disclosure requirements are unlikely to achieve this goal. A recent report by the Group of Thirty emphasized that additional disclosure requirements could add to confusion instead of enhancing transparency. ${ }^{2}$ Even without government regulation, financial institutions still have strong incentives to disclose information - notably, the need to attract capital. Market mechanisms could prove to be more efficient than the imposition of overly detailed disclosure requirements that, in their totality, could become overwhelming.

The main economic rationale behind prudential regulation of the banking sector is to ensure stability of the financial system. This topic has been on the agenda of the

\footnotetext{
${ }^{2}$ Group of Thirty (2003).
} 
Financial Stability Forum for some time. Central banks and banking/securities regulators worldwide have long experience in implementing measures to prevent systemic crisis. They supply sufficient liquidity to global financial markets, or come to the rescue of individual firms where stability concerns justify a bailout.

Stability issues have also been raised as a prudential concern with respect to reinsurance, although there is no empirical evidence that reinsurance constitutes a systemic risk to the financial system. ${ }^{3}$ This perception was driven mainly by the growing amount of credit risk that banks transferred to non-banks, in particular through credit derivatives. Banking regulators doubted the reinsurers' ability to manage such risk. Today, leading representatives of regulatory bodies and central banks are beginning to recognize that the insurers' and reinsurers' role as 'protection sellers" in credit derivatives transactions has been overstated and should not be regarded as a major concern. To the contrary, the reallocation of credit risks between the banking and insurance sectors appears to have enhanced financial stability. This beneficial impact of cross-sector risk transfers has also been recognized by the IMF. ${ }^{4}$ The IMF assessment takes into account that the credit risk net positions in the insurance sector is only a small part (3-4 per cent) of its entire asset portfolio. The credit instruments' relatively low volatility and their known cash flows have proven beneficial for insurance companies to match against long-term liabilities. As a positive side effect, the insurance companies' involvement in credit instruments has encouraged them to develop advanced credit risk management skills.

Regulatory actions must also be seen in the context of overall social and economic policy. Financial services are essential for economic growth and prosperity, and ensuring an orderly state of affairs in the sector is a legitimate regulatory goal. Yet in some instances, policymakers might be tempted to regulate financial services for reasons other than prudential objectives. Certain rules could be designed to protect various special interests - to provide affordable credit facilities to smaller and medium-sized enterprises, for example. In the insurance sector, compulsory insurance schemes also serve outside policy objectives; regulation of life insurance and pension fund markets has a clear link to social security policy. It is important for policymakers to avoid any negative repercussions that such rules may have on market efficiency.

\section{Economic impact of regulations}

Financial institutions are very sensitive to regulation. Changes to the regulatory environment often create incentive structures that have an immediate impact on financial service supply and demand; they could even lead to a geographic reallocation of financial service providers. Thus, policymakers and policy analysts increasingly acknowledge the need to evaluate and anticipate the business impact of proposed regulations before their adoption. Such an analysis is an essential element of sound regulatory governance.

\footnotetext{
${ }^{3}$ Swiss Re (2003).

${ }^{4}$ IMF (2004).
} 
In the EU, regulatory impact assessment is today an integral part of the legislation process, although there are still shortcomings in applying this instrument in practice. The "Four Presidencies Initiative" has given fresh impetus to improving the quality of European regulations. ${ }^{5}$ It is drawing particular attention to the formal quality control of EU legislation through meaningful Extended Impact Assessments. A recent study by the Corporation of London provides an update on the current state of regulatory impact assessments in Europe and further develops the tools and techniques used in measuring economic impact. ${ }^{6}$ The findings of this study are of particular relevance to the regulation of the financial services sector.

It is the U.K.'s Financial Services Authority (FSA) which presently has what is probably the most advanced approach to measuring the impact of new prudential legislation. ${ }^{7}$ The key element of a regulatory impact assessment is a cost-benefit analysis of the proposed regulations: it means simply that lawmakers must endeavour to quantify the public good that the regulation aims to achieve and to balance this with the direct and indirect costs of the regulatory action. This allows policymakers to make a knowledge-based judgement as to the proportionality and cost-effectiveness of a proposed regulation. Such a pre-assessment forces lawmakers to consider alternatives capable of achieving the same public policy objective - measures that are less onerous for the business but equally effective.

Comprehensive cost-benefit analyses are particularly challenging in the case of complex regulatory reform projects, such as the elaboration of international accounting standards or the introduction of a risk-based capital regime (Basel II and Solvency II, respectively). A recent study estimated that in order to comply with the new Basel Capital Accord, EU banks and investment firms would spend between 20 and 30 billion euros between 2002 and $2006 .{ }^{8}$ The study concluded that the overall balance of costs and benefits was positive. In contrast, many market participants have voiced concern that Basel II is too prescriptive, too costly to implement, and that it would generate excessive bureaucracy.

While direct compliance costs can be measured - approximately - in monetary terms, it is much more difficult to measure macroeconomic benefits and costs. Any attempt to place a monetary value on the wider macroeconomic effects of a regulation poses methodological problems: how, for example, can we measure the pro-cyclical effect of a risk-based capital system? Or what is the monetary value of the welfare loss that results when overly protective regulations restrict competition?

As to the macroeconomic consequences of Basel II, the study mentioned above found that limiting its application in the U.S. to only a few internationally active banks would not put European financial firms at a significant competitive disadvantage. Further, the report maintains that pro-cyclicality can be mitigated by supervisory stress testing with longer time horizons and, where minor changes in

\footnotetext{
5 The "Four Presidencies Initiative" is a joint regulatory reform effort that was launched in January 2004, so named because it was instigated by the finance ministers of the four EU member states who succeeded each other in the EU presidency: Ireland, the Netherlands, Luxembourg, and the United Kingdom.

${ }^{6}$ Mather and Vibert (2004).

${ }^{7}$ Alfon and Andrews (1999).

${ }^{8}$ Price Waterhouse Coopers (2004).
} 
creditworthiness occur, by flattening risk curves for credit risk exposures that would not produce large changes in capital requirements. It remains to be seen whether these qualitative assessments will be confirmed by experience.

In sum, it remains difficult to quantify the macroeconomic impact of the new riskbased capital regulations. However, systematic and thorough business impact assessments, even if their outcome is only a rough approximation, are a powerful public policy concept for avoiding over-regulation, and ultimately, for achieving better regulation.

\section{Regulatory impact on the management function}

Given the amount of new financial sector regulation and the sheer volume of the accompanying paperwork, it is not easy for regulated companies to maintain a broad view of the implications for their business. Top managers who find themselves under increasing pressure just coping with short- to medium-term compliance challenges might find it helpful to prepare a comprehensive regulatory risk landscape for their firm.

No doubt, the current regulatory reform process will strongly influence the behaviour of financial service enterprises. In some companies, the implementation of new regulations may accelerate internal measures that are overdue. Indeed, the introduction of the new risk-based capital regime is likely to trigger a "change management" process in many financial firms. It could force senior management to reconsider the company's business strategy and business mix. It could induce them to reallocate resources (both capital and human) and adjust the firm's internal organization and processes: for example by enhancing the risk management function or their compliance organization. In the case of complex financial groups, it could trigger an adjustment of the company structure. In any event, financial services firms will need to spend significant sums and commit considerable resources to enhance their systems and processes and build up the technical skills necessary to meet the new prudential requirements.

For many firms, implementation of the new capital adequacy and risk governance rules will lead them to improve their processes for assessing risk and pricing capital. From a conceptual standpoint, it should result in more efficient capital allocation; it should also enhance financial stability, assuming that more sophisticated risk management capabilities will make a firm more robust. However, expenditure and benefit will not always stand in reasonable relationship. In addition to compliance costs, companies will also bear the opportunity costs: the management resources absorbed by dealing with regulatory issues mean less capacity to pursue other (more profitable) commercial objectives.

One purpose of the new prudential requirements is to increase managers' exposure both to financial and reputational risk. The idea is to avoid excessive risk-taking and to reduce the risk of failure. However, such a system also has a formidable downside potential. There is a danger that tight requirements for capital adequacy and disclosure, coupled with a rigid risk governance regime, will discourage financial companies from risk-taking. This could have negative economic consequences. Where companies are no longer prepared to accept risk, there is no growth 
perspective. Well-intentioned regulations could thus ultimately stifle economic prosperity. Reinsurance companies have seen their expansion into new markets alternative risk transfer, or ART, for example - which not only attract the attention of international regulatory bodies, but also serve as a pretext for tightening prudential supervision. This experience has certainly dampened efforts to invest in innovative financial products and even prompted certain market players to withdraw from profitable market segments such as the credit derivative business.

Against this background, regulators and international standard-setters need to be mindful that their policy statements may be regarded as early warning of increased regulatory scrutiny. Many market participants, especially investors, perceive tighter prudential control as detrimental to a sector's profitability and competitiveness. Yet even when the economic impact of regulatory intervention is insignificant, the market immediately anticipates it as a potential harm, and reflects it in share prices of the sector.

Regulations have incentive properties, and for this reason the interaction between regulations and market conduct has been receiving greater attention. Ideally, regulation should aim at creating the right incentives, not at perfecting market mechanisms: there is no such thing as a perfect market. Any regulatory framework aimed at removing all transaction inefficiency or information asymmetry, real or imagined, would be overly tight.

Nevertheless, current regulatory trends are heading in this direction. The draftsmen of a risk-based capital regime for both the banking and the insurance sectors are creating pressure for increased accuracy in risk-factor measurements and the related capital weightings. This puts greater emphasis on detailed, complex rules. This tendency towards "micro-prudential" supervision conflicts with policy papers calling for a "non-zero-failure" policy. It is also inconsistent with public statements emphasizing the advantages of a principle-based (as opposed to a prescriptive) prudential framework. Regulatory perfectionism is also incompatible with a "marketbased approach", an often-praised concept directed at correcting substantial market imperfections, but no more. At the heart of a market-based approach are public disclosure provisions aimed at enhancing market discipline. However, policymakers should not push disclosure requirements too far, as this could lead to information overload and ultimately reduce transparency. Excessive public disclosure requirements are counterproductive; for example, the disclosure of stress testing could discourage insurance companies from testing truly adverse scenarios.

These public disclosure provisions must be distinguished from prudential disclosure, which is intended for the regulator alone, not for publication. The disclosure of risk exposure data is an intrinsic part of the risk-based capital system; only a well-informed supervisory authority would be able to enforce regulations on capital adequacy and risk governance. Yet much of this detailed information on underlying risk factors and their measurement is highly sensitive. Indeed, under an advanced risk-based regulatory model, the supervisory authority would know almost as much as senior management about a firm's financial and operational risks.

As a result, the supervisor would suddenly find himself in a position very close to that of management. It is conceivable that, equipped with the power to intervene, a fully informed regulator could simply capture command of the firm. Although regulators may not be keen to assume such a steering role, their intimate knowledge of 
sensitive risk information would place considerable responsibility on their shoulders. Could a regulator remain passive if he saw a company taking excessive risks? Wouldn't the public expect a fully informed regulator to bring into play the full range of instruments at his disposal, to correct the company's course and eliminate lapses of conduct? Could a regulator be held accountable if he did not interfere? A supervisory authority might feel itself under considerable pressure to take remedial action, probably at too early a stage. It is thus understandable that regulators have begun to dampen such expectations by emphasizing that they cannot prescribe the precise conduct appropriate for every circumstance. ${ }^{9}$

Yet the dynamics of regulatory interference under an advanced risk-based capital regime could be more subtle. There is reason to believe that the executive management of many financial firms attach too much importance to regulatory outcomes, that is, they attempt to reconcile each and every operational or strategic decision with considerations of regulatory policy. Arguably, when a company refrains from pursuing a promising business opportunity simply because the regulatory capital charge is high, its capital allocation becomes less efficient. It would be even worse for the company to take on too much of a particular type of risk just because the capital weightings are low. A similar incentive/disincentive mechanism is known with rating agency assessments of business transactions. Likewise, under a stringent prudential regime, the management of a financial firm could feel constrained to be overly riskaverse. Such behaviour would undermine the commercial foundation of its business: to create value for shareholders by taking on and pricing risks.

\section{Conclusion}

A closer supervisory relationship is a characteristic feature of the risk-based capital approach in the insurance and banking sectors. Yet it will be important not to lose sight of the regulatory bodies' increasing influence, especially to prevent the regulators from tacitly capturing the management function. While it is the regulator's job to exercise oversight over the processes and control mechanisms of the companies they regulate, it must be perfectly clear that the ultimate responsibility for risk and capital management resides with corporate management. It is management, not the regulator, who is held accountable for business decisions. Thus, it is essential for supervisory authorities not to become involved in managerial decision making.

An advanced regulatory framework, per se, is not harmful for financial firms, as it preserves a certain level of confidence and trust - and this is very much in the interest of the industry. However, the increasing intensity of supervision we are seeing now may effectively restrict risk transfer between different market players, or between different financial sectors. Regulatory constraints on the transfer of risk across the financial system works against system stability, and are thus counterproductive. Risk does not just disappear from the system: curbs on risk transfer would only tend to concentrate it in certain sectors. Policymakers must be aware that the freedom of risk

\footnotetext{
${ }^{9}$ FSA (2003).
} 
42

transfer enhances overall risk diversification. It is crucial for the long-term success and stability of financial markets worldwide to give risk transfer transactions enough freedom to satisfy market demand.

There is growing awareness that a market-based approach to regulation - one that encourages risk diversification, as opposed to one that stipulates a tight, prescriptive prudential rulebook - could be more efficient at maintaining financial stability. From a conceptual point of view, this means that the micro-prudential focus of risk-based supervision should be shifted to a more macro-prudential approach based primarily on incentive structures. ${ }^{10}$ This implies that economic impact assessments should be improved, made even more meaningful, and integrated into the international standard-setting process. We consequently propose a leading role for the OECD as an independent review body for regulatory governance, particularly in the financial services sector.

\section{References}

Alfon, I. and Andrews, P. (1999) 'Cost-benefit analysis in financial regulation', FSA Occasional Paper 3(September).

Crockett, A. (2000) Marrying the Micro- and Macro-Prudential Dimensions of Financial Stability speech to the 11th International Conference of Banking Supervisors, Basel, 20-21 September 2000, (www.bis.org/ speeches).

FSA (2003) Reasonable Expectations: Regulation in a Non zero Failure World (September).

Group of Thirty (2003) Enhancing Public Confidence in Financial Reporting, Washington, DC.

IMF (2004) Global Financial Stability Report (April).

International Association of Actuaries (2004) A Global Framework for Insurer Solvency Assessment.

Mather, G. and Vibert, F. (2004) 'Reducing the regulatory burden: The arrival of meaningful regulatory impact analysis', Corporation of London (July).

Price Waterhouse Coopers (2004) Study on the Financial and Macroeconomic Consequences of the Proposed New Capital Requirements for Banks and Investment Firms in the EU (MARKT/2003/02/F).

Swiss Re (2003) Reinsurance - A Systemic Risk? sigma No. 5.

\footnotetext{
${ }^{10}$ Crockett (2000).
} 